\title{
Migrant Knowledge Workers' Perceptions of Housing Conditions in Gulf Cities
}

\author{
Ashraf M. Salama ${ }^{1}$ - Florian Wiedmann ${ }^{1}$. \\ Hatem G. Ibrahim ${ }^{2}$
}

Published online: 18 September 2017

(C) The Author(s) 2017. This article is an open access publication

\begin{abstract}
The various efforts in diversifying local economies in most Gulf States led to the emergence of new medium to high-income groups of migrant knowledge workers whose efforts are required to develop various new economic sectors. This paper aims to investigate the current housing conditions and perceptions of these migrant communities to identify key similarities and differences with respect to housing made available to them and depending on their cultural background. To this end, the methodology involves field surveys to explore the three main housing typologies for higher-income groups and a questionnaire with a total of 258 knowledge workers in the city of Doha as a representative case to investigate the associated perceptions of four dominant groups from different cultural backgrounds. The findings reveal that there is a distinct social segregation between cultural groups, which is mainly rooted in varying income levels. Furthermore, the supply-driven market has hardly integrated cultural needs of migrants and thus diversified and inclusive housing has been identified as major planning and design challenge.
\end{abstract}

Keywords Housing · Migrant knowledge workers · Multiculturalism · Urbanism · Gulf · Qatar

Ashraf M. Salama

ashraf.salama@strath.ac.uk; asalama@gmail.com

Florian Wiedmann

florian.wiedmann@strath.ac.uk

Hatem G. Ibrahim

hatem_ibrahim@qu.edu.qa

1 Department of Architecture, University of Strathclyde, Glasgow, UK

2 Department of Architecture and Urban Planning, Qatar University, Doha, Qatar 


\section{General Housing Development Patterns in Gulf Cities}

Since the oil production and the first modern urbanization period during the middle of the twentieth century, Gulf countries have witnessed a continuous and extensive migration from various regions worldwide. While advanced service sectors have initially attracted migrants from the wider Middle Eastern region, lower economic sectors have traditionally been occupied by laborers from South Asia (Gardner 2011, p. 3). During these first decades of oil production and extensive migration, the main development goal of governments was the completion of a functioning infrastructural backbone and the establishment of independent national states (Scholz 1999).

The implemented mechanisms of the welfare state led to a rapid supply of modern suburban neighborhoods for the native population due to public housing programs and strategies. The inner-city areas were subsequently occupied by mixed-use developments and densely populated areas for lower-income guest workers (Salama and Wiedmann 2013, p. 31). The transition zones along the central areas towards the urban periphery were inhabited by migrant families with higher income. This typical structure often followed the location and positioning of first industrial areas. The location of heavy industries, such as the aluminum production, defined the distribution of new housing areas in Gulf cities (Scholz 1999, p. 77). It is continuously argued that the first decades of urbanization led to two forms of social segregation, which have however proven to be convergent: the segregation between migrant and native communities and the segregation between income groups (Dresch 2006, p. 201).

The various national housing policies and acts led to a quick supply of plots to local populations (Al Buainain 1999, p. 92). The small plot sizes in downtown areas and the missing supply of sufficient road infrastructure on top of the complex organic structure of previous traditional settlements were additional factors for the rapid development of new suburban areas. These modern suburban neighborhoods were initiated to appease the native populations during the first fragile years of national independence and the installation of new political systems (Scholz 1999, p. 51). The suburban housing typology was first introduced in the Gulf region by oil companies, who had to develop new large-scale settlements in proximity to the actual oil exploration activities.

Speculative tendencies led to a rapid increase of urban sprawl along the periphery of Gulf cities. In parallel, the old downtown areas witnessed a complete replacement by modern cement buildings and first large apartment blocks (Wiedmann et al. 2013, p. 28). The first apartment blocks were built to accommodate low- to medium-income migrant groups, while most migrants with higher income preferred to live in compounds in areas close to business districts. These compounds were gated and thus provided a certain level of privacy and openness to various lifestyle choices. According to Salama and Wiedmann (2013, p. 31), the first modern urbanization period led to three new housing typologies in Gulf cities replacing the traditional typologies: Suburban individual dwellings gated compounds mostly away from urban centers and apartment blocks in downtown and industrial areas.

During the 1990s, the Emirate of Dubai initiated a new phase in the evolution of Gulf cities. The general vision to establish a hub inviting international tourism as well as foreign investment led to an extensive construction boom resulting in an increasingly diverse housing market. The first project offering freehold properties for foreign investors is known as Emirates Hills, which was built in 1999 and marked a new 
urban extension in Jumeirah (Wiedmann 2012, p. 56). The subsequent developments followed the general idea of creating themed and often gated neighborhoods in proximity to waterfronts to generate the image of exclusivity and uniqueness (Schmid 2009, p. 57, Wiedmann et al. 2014, P. 64). The first peak of this development, the Palm project, was the first iconic housing development on reclaimed islands. Another new phenomenon was the construction of exclusive residential high-rise projects in Jumeirah, such as Dubai Marina (Fig. 1), which added a new residential typology in the Gulf region. The large-scale development sites in Dubai Jumeirah are the first prototypes of a completely new direction of an increasingly dynamic housing market mainly driven by regional investors (Salama 2011). Subsequently, this tendency has led to an increasing discrepancy within the housing markets and an oversupply of exclusive properties, which led to a significant price drop of real estate during the international financial crisis in 2008 (Bertrand 2012).

Today, decision-makers in both private and public sectors need to react on new demand-driven aspects within housing markets to attract individual long-term investments and to reduce speculation-driven projects. Therefore, the paper aims to deliver new insights regarding the current housing typologies and the associated perceptions of housing conditions by migrant knowledge workers. This social group and its long-term settlement in Gulf cities are crucial for the economic diversification process. An attractive and responsive housing market is an important factor in increasing the overall livability. Since this social group consists of migrants with various cultural backgrounds, the paper attempts to investigate the key differences of housing conditions and perceptions in the context of four major cultural groups in Gulf cities.

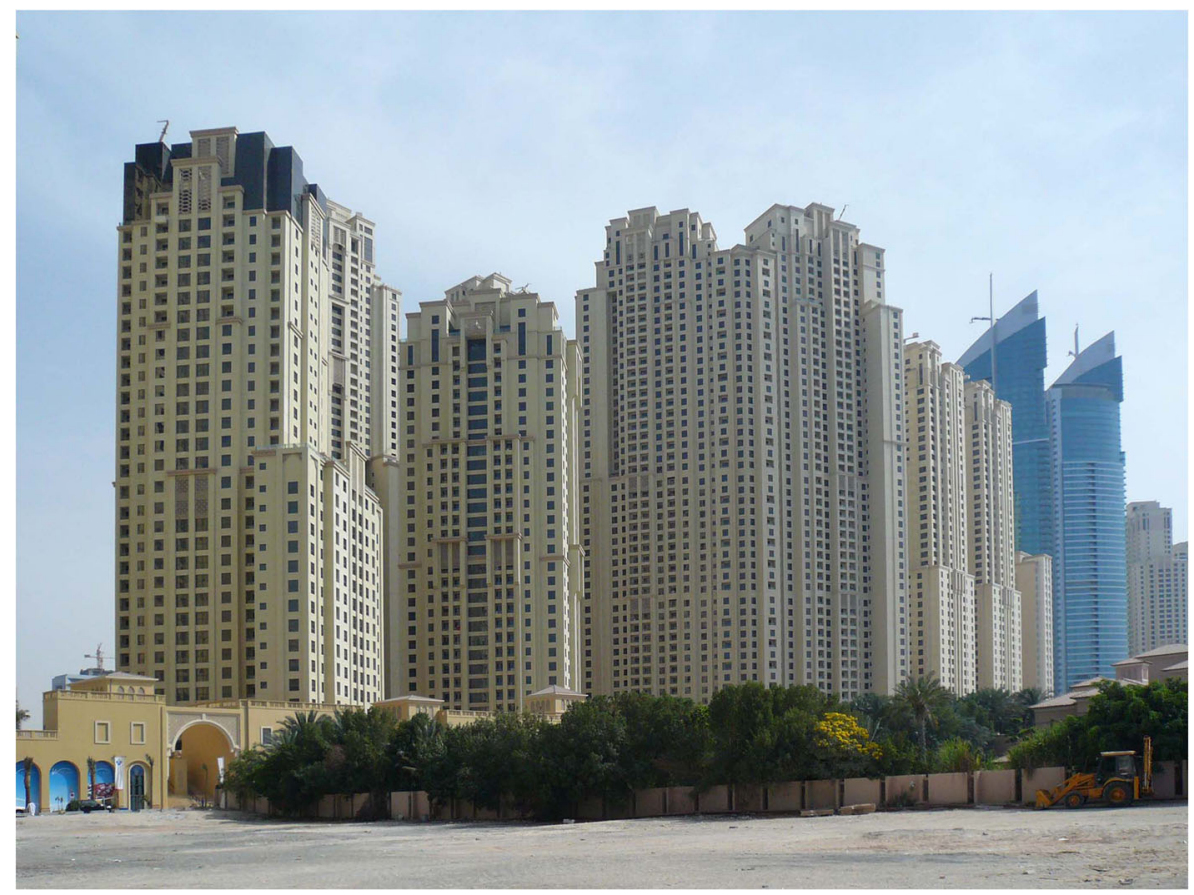

Fig. 1 Residential high-rises in Dubai (source: authors) 


\section{Migrant Knowledge Workers in Gulf Cities}

Over the past few decades, the modern globalization process has initiated an increasing competition between cities worldwide leading to a hierarchy of highly networked cities. This phenomenon has been described by Friedmann (1986) as the "World City Hypothesis," which is rooted in the earlier writings of Castells (1972) and Harvey (1973), who have initiated a new thinking of global urbanization by seeing cities as products of social forces set in motion by the new global capitalist relations of production (Friedmann 1986, p. 69). Modern infrastructure and the gradual liberalization of markets have enabled businesses to explore the best places for industrial production as well as the concentration of advanced producer services. Consequently, entire industries moved to places with a sufficient supply of cheap laborers and infrastructure, while key service sectors expanded in important international hubs.

Sassen (1988 and 1991) added her views on the impact of international investment and subsequent migration patterns as well as the emergence of global cities. This migration aspect has been explored earlier by Cohen (1981), who introduced his theories on the international division of labor and the resulting social imbalance between the developed and developing world. Cities have therefore been identified as key nodal points coordinating and defining the new spatial distribution of global economies. In order to enter a major role within international networks, cities, according to Taylor (2003), need to attract the headquarters of companies within advanced service sectors, which are generally referred to as knowledge economies (Salama et al. 2016).

The growth of knowledge economies is mainly dependent on a high concentration of knowledge workers, who are recruited worldwide. Richard Florida (2002) refers to these groups as the "Creative Class." He introduced the notion of how these knowledge workers are the main drivers of urban regeneration processes due to demand-driven dynamics. Despite various cultural backgrounds, migrant knowledge workers are generally perceived as a social force generating integrated rather than segregated forms of urbanism due to their leisure time and financial opportunities resulting in social and economic interaction. Nevertheless, this notion has been mainly tested in the Global North rather than in emerging cities in the Global South, where development dynamics are often dictated by short-term mechanisms of instant urban growth rather than the long-term evolution of migrant communities. In this respect, Sanderock (1998) states that there is an increasing challenge in many cities worldwide to develop cosmopolitan societies due to rapid and extensive migration and the emergence of fragmented and segregated cultural groups.

The preceding discussion suggests that the cities in the Gulf region manifests an important case for exploring migrant knowledge workers in emerging cities in the Global South and the small Arabian Gulf States, such as Qatar, UAE, and Bahrain. These countries share their history as oil-producing nations and a rapid modernization process during the last three or four decades. Particularly, during the 1990s, a new vision has been introduced to establish Gulf cities as international hub cities for global trade, culture, tourism, and investment (Fox et al. 2006). While the previous social structures were mainly built on native communities living in welfare state structures and migrant labor supplying the manpower to sustain and build modern urban 
environments as well as being engaged in the oil production and associated industries, the new vision of hub cities has led to major investments of oil revenues in establishing new highly developed economic sectors, such as logistics, finance, and high-tech industries. Due to the limited number of local populations and their professional qualification, these new economic diversification strategies have been dependent on a rather diverse group of migrants with various cultural backgrounds (Sulayman 2006, p. 259). According to a study of UNICEF in 2013, 88\% of Qatar's population (2.2 million in total) were migrants in comparison to $55 \%$ in Bahrain and $84 \%$ in the UAE (DESA 2013).

In addition to educated workforce from the Indian subcontinent and the Philippines, many migrants in high-economic sectors originate from Egypt and the Levant region as well as Europe, USA, and Australia. The main migrant groups in Qatar are from the Indian subcontinent constituting around $51 \%$ of the entire population, followed by migrants from Egypt (8\%) and the Philippines (9\%). All migrants from North America, Europe, and Australia constitute 3.1\%. Qatar is furthermore an example of a rather high diversity of migrant groups, who arrived in recent years. Today, migrants from more than 64 nations reside in the small emirate (BQ Magazine 2014; DESA 2013). The main motives to relocate to the Gulf region are the high-income level in comparison to home countries, the possibility to gain working experiences in certain sectors and the provision of general security, as well as a modern infrastructure. Due to the geopolitical location and expanding airline enterprises, Gulf cities are furthermore perceived as highly accessible and connected by this very mobile international workforce. Today, economic development agencies, such as the General Secretariat of Development Planning (2008) in Qatar or the Abu Dhabi Council for Economic Development (2014, p. 23), have identified the importance of the international knowledge workers for a successful economic diversification. One key factor in this regard is the development of a high level of quality of urban life attracting and integrating various cultures and lifestyle choices.

A key pillar for establishing livability in cities worldwide and Gulf cities are no exception is an affordable, diverse, and attractive housing supply (Choguill 1996). Therefore, housing studies need to be rooted in a comprehensive understanding of contemporary housing conditions and the associated perceptions (Bonaiuto et al. 1999). The one-dimensional approach of investigating housing typologies needs to be extended by examining the views of various social groups (Butler et al. 1969). Thus, a comparative assessment needs to be applied, particularly in the case of immigrants and rather differing cultural backgrounds, to identify key characteristics and thus new dynamics. Various studies (Hui et al. 2012; Balbo and Marconi 2006; Owuso 2010) have been carried out to investigate the interdependencies between housing conditions and individual perceptions resulting in new spatial development patterns in migrant cities worldwide. This paper thus aims to add new empirical evidence in the case of the Gulf region.

\section{Case Study: Qatar's Capital Doha}

\section{Methodological Approach}

Qatar's capital Doha has been chosen as case study due to the very particular scale of migration that took place in recent years. Between 2003 and 2015, the population of 
Doha's metro region has increased from less than 700,000 to more than 1.8 million inhabitants, of which almost $90 \%$ are migrants (BQ Magazine 2014). The rapid growth in recent years and the ambitious plans to establish new economic sectors have led to a high diversity of migrant groups with medium- to high-income. Thus, more than 50 companies within advanced producer service sectors, such as finance and engineering, have been asked to participate in a questionnaire survey on housing since 2013. In total, 352 employees participated in this survey. After a first assessment of the reactions to the questions, 258 responses were identified as completely valid for an effective comparative analysis. The main selection criterion was the completion of the entire questionnaire.

The questionnaire addresses important housing-related factors, yet developed following a simple structure, which is focused on exploring the main housing conditions and perceptions of each participant (Table 1). The questionnaire has been elaborated by evaluating earlier empirical research using a large group of participants, such as the work of Ukoha and Beamish (1997). Therefore, each participant has been first asked to state the general information of both themselves and their current residence, before they were asked about their general level of satisfaction and the main reasons. On this basis, the questionnaire is constituted in three main parts that can be outlined as follows:

A. The first part of the questionnaire addresses the profile of each participant based on key characteristics, such as his or her nationality, gender and age, as well as the length of stay in Doha. As part of the profile information, owning a car is also an important parameter.

B. Placing emphasis on the current housing type and its location, the second part of the questionnaire seeks information on whether a certain level of social segregation exists based on residence preferences and income differences.

Table 1 Summary of all questions of the applied questionnaire (source: authors)

Part I: general information

Your country of origin?

Your gender and age?

How many years have you been in Qatar?

Do you drive a car?

Part II: housing conditions

Did you choose your residence?

In which type of residence do you live?

Where is your residence (district)?

Part III: housing perceptions

Your general satisfaction in comparison to your previous residence (country of origin)?

Are you satisfied with the general layout and room sizes?

Are you satisfied with your neighborhood surroundings and supplies?

Are you satisfied with the utilities? Is there sufficient access to daylight?

Are you satisfied with the exterior and interior design of your residence? 
C. With the aim of identifying commonalities and differences among cultural groups while conceiving key challenges for improving hosing conditions, the third and last part of the questionnaire tackles the way in which housing conditions are currently perceived including layout, design, as well as neighborhood surroundings.

\section{Discussion of Major Findings}

The analytical procedure involved scrutinizing these general characteristics to distinguish four main cultural groups representing the migrant knowledge workers and key differences between these groups with respect to gender, age and years living in Doha, as well as car ownership. Coupled with the analysis of the frequency of responses, a GIS map was evaluated with respect to the distribution of certain housing areas. The map was furthermore utilized to locate the respondents' residences to illustrate the spatial distribution in the key housing areas for medium to high-income groups. Subsequently, the various housing areas were visited to examine the various typologies and their neighborhood contexts. These field visits aimed at establishing generic yet key characteristics of new migrant housing areas in Doha. Findings resulting from the analysis are classified in three categories that include the profile of migrant groups, housing conditions as manifested in contextual and typological aspects, and perceptions of housing conditions.

\section{The Profile of Surveyed Migrant Groups}

After the initial selection of 258 interviewees, four key migrant groups could be identified. Forty-four respondents have a European descend, mainly from the UK (55\%). The remaining share includes Germans, French, as well as Dutch migrants. The second group identified is 44 respondents from Egypt (23\%) and the Levant region, mainly from Lebanon (32\%). The largest group with 96 respondents has an Indian origin and the second largest group is from the Philippines (74 respondents).

All four groups share one important aspect, that they have lived in average less than 15 years in Doha and that they earn a medium to high income due to their professional occupation permitting them to move their families to Doha (Table 2). However, it must be stated that the country of origin has a significant impact on the average salary in the case of similar working positions. This is mainly based on the various perceptions of attractive salaries in the migrants' home countries and the willingness to accept the living and working conditions in Gulf cities. Respondents from India, for instance, have emphasized their very positive impression of a high level of security in Doha, while Europeans have emphasized their high salaries as their main motive to live in the Gulf region.

The analysis reveals that the average age of Europeans is the highest, which is an indicator for a large share of senior employees, who are attracted to work in Doha before their retirement. The youngest average age can be found in the case of respondents from Egypt and the Levant, which is an indicator for the general attractiveness of Gulf cities to gain working experience and better living and working 
Table 2 The general characteristics of the four migrant groups of interviewees (source: authors)

\begin{tabular}{llllllll}
\hline Origin & $\begin{array}{l}\text { Numbers of } \\
\text { participants }\end{array}$ & $\begin{array}{l}\text { Gender } \\
\text { Male Female }\end{array}$ & Average age & $\begin{array}{l}\text { Average } \\
\text { number } \\
\text { of years in Qatar }\end{array}$ & $\begin{array}{l}\text { Car } \\
\text { ownership rate }\end{array}$ & $\begin{array}{l}\text { Free } \\
\text { residence choice }\end{array}$ \\
\hline Europe & 44 & $65 \%$ & $35 \%$ & 37 & 2.7 & $86 \%$ & $80 \%$ \\
Egypt and & 44 & $59 \%$ & $41 \%$ & 31 & 7.7 & $91 \%$ & $89 \%$ \\
$\begin{array}{l}\text { Levant } \\
\text { India }\end{array}$ & 96 & $80 \%$ & $20 \%$ & 34 & 7.6 & $68 \%$ & $79 \%$ \\
Philippines & 74 & $45 \%$ & $55 \%$ & 35 & 4.4 & $46 \%$ & $77 \%$ \\
\hline
\end{tabular}

conditions than those they have in home countries. While Europeans have stayed the least average number of years in Doha, the Arab respondents have stayed the longest average period of almost 8 years, which is a further indicator of a high share of young migrants focusing on building their careers in the Gulf. The relatively high number of years residing in Doha in the case of the Indian migrants can be interpreted as a generally attractive option to stay in the Gulf instead of moving back to India, while Filipinos have the tendency of staying a few years in Doha, which can be attributed to the significant cultural differences as well as the fact of the high female percentage within this group.

The highest share of female employees can be found in the case of the Filipino respondents, who are mostly employed as accountants. The lowest share of female employees can be found in the case of the Indian respondents, who are mainly employed as engineers. The most balanced share of female and male employees can be found in the case of Arab employees, who occupy a high diversity of different professions, while the high share of management positions in construction related businesses explains the rather low share of female employees in the case of the European respondents group. The lowest ownership rate of cars can be found in the Filipino group, which is influenced by the high share of female employees and the general willingness to share a driver or a taxi. The highest rates can be found in the case of the Arab interviewees as well as Europeans, who prefer to live in suburban areas and heavily rely on their own cars.

Most respondents have a free choice regarding their residence. In the case of the Filipino group, approximately $23 \%$ have accommodation provided by their employers, while only $11 \%$ of the Arab respondents are living in housing units rented or owned by their employers. The relatively high share of respondents, who needed to look for an accommodation in Doha, is an important indication that the housing market for migrants is increasingly developed and that employers prefer to offer fixed housing allowances instead of providing accommodations due to continuously increasing rents in recent years.

\section{The Contemporary Housing Conditions}

The analysis conveys that there are currently three main housing location options for medium- to high-income groups within the metro region of Doha: The city districts 
along the four main ring roads, the suburban extensions in the North and West, and the new waterfront districts in West Bay along the Northern shoreline. According to a GIS survey, around $91 \%$ of all residential areas are occupied by low-rise, $8 \%$ by mediumrise, and $1 \%$ by high-rise developments. The biggest share of all interviewees is residing in apartment blocks and high rises within the downtown areas, particularly along C-Ring Road and Al Sadd (Fig. 2). The area has previously been Doha's low-rise urban periphery until the construction boom commenced in 2003 and the suburban sprawl has shifted towards newly developed areas in the North and West of Doha. Today, recent zoning changes have led to a high density of residential blocks and high rises in inner district areas and an increasing number of commercial developments along the main road grid. Most offices are currently located along C-Ring Road due to its high level of accessibility (Mirincheva et al. 2013).

The more moderate rental rates in areas in proximity to Doha's center have attracted low- to medium-income groups, particularly from India and the Philippines. Europeans typically avoid these neighborhoods due to traffic concerns and the lack of certain housing typologies, such as compounds. The Arab respondents are interested to move to these areas due to well-integrated services and familiar surroundings. The lack of implemented building restrictions has led to rather low distances between multistory buildings of sometimes less than $5 \mathrm{~m}$. Many residential buildings reach heights of 11 floors leading to a high percentage of shaded facades with limited supply of daylight (Fig. 3). Field surveys indicate that these high-built densities and improvised parking areas have led to a chaotic environment lacking pedestrian-friendly walkways. While commercial services, such as restaurants, are integrated, most areas lack social infrastructural facilities and green areas.

The new suburban areas in the North and West of Doha are occupied by two main typologies: the stand-alone villas of mainly Qatari neighborhoods and various compound developments for medium- to high-income migrants. The largest concentration

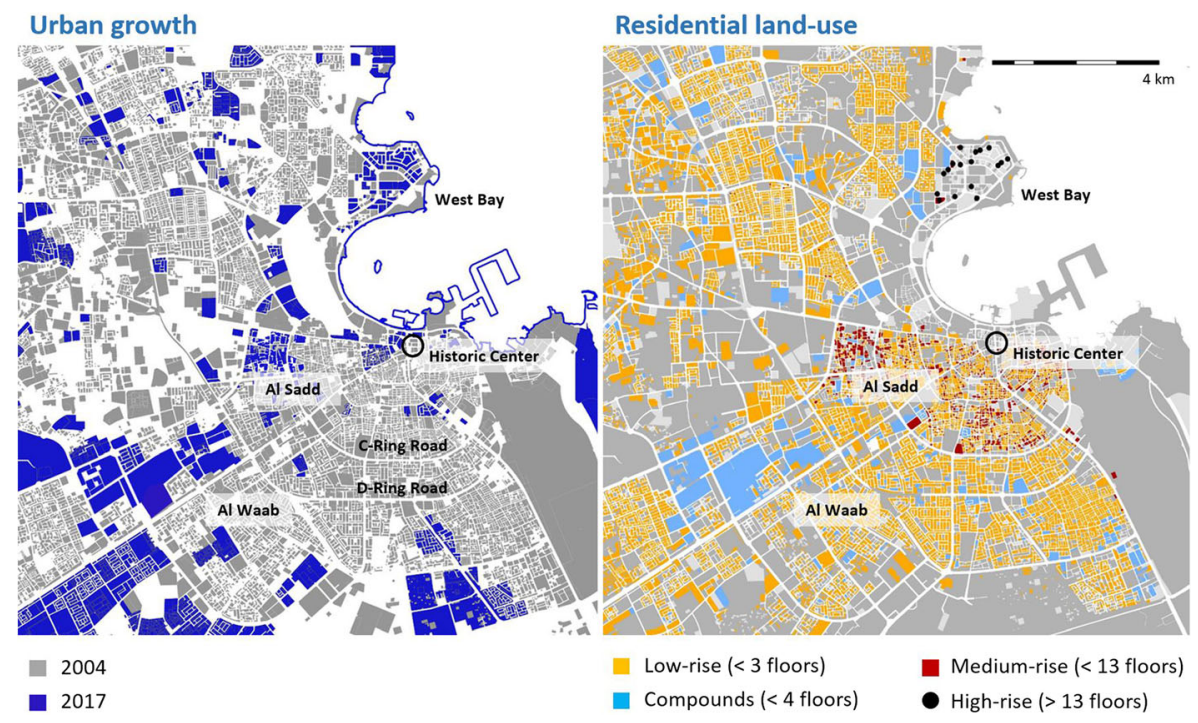

Fig. 2 The newly added urban areas since 2004 and the distribution of residential land uses in Doha (source: authors, Google Earth) 


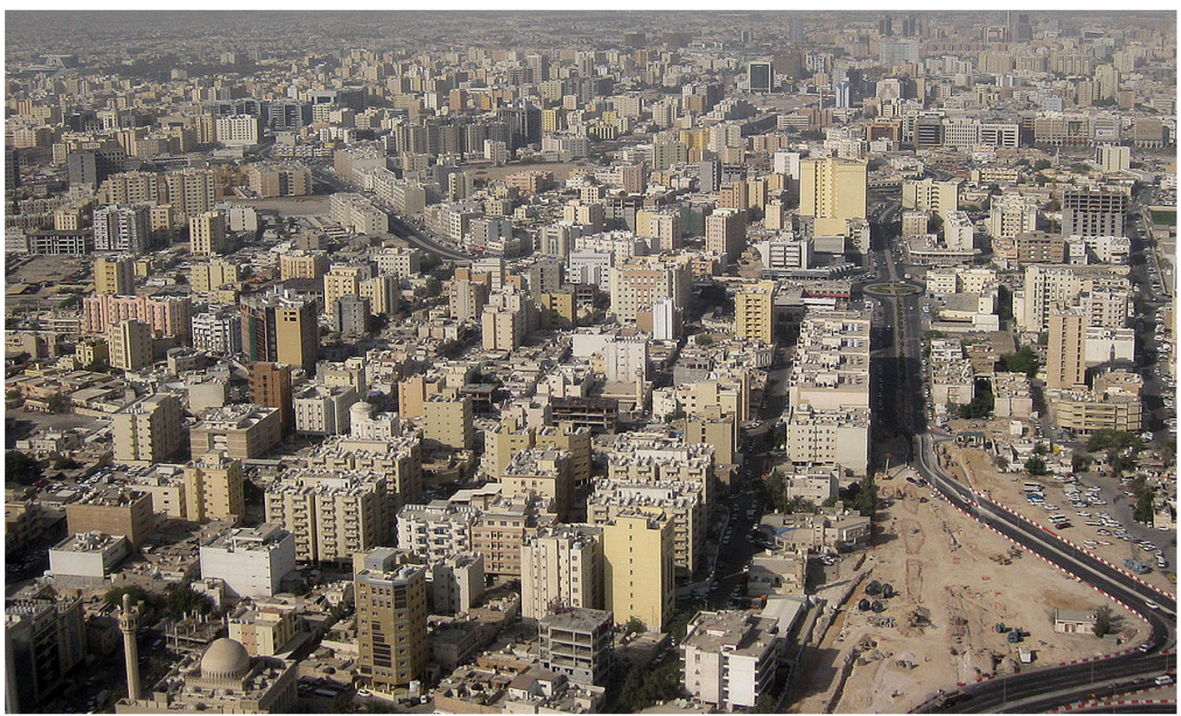

Fig. 3 Residential blocks and high rises in inner-city districts (source: authors)

of compounds can be found in proximity to the Aspire Zone, the Al Waab district, where the 2006 Doha Asian Games took place (Fig. 4). The new infrastructural development at the beginning of the millennium and the exponentially increasing housing demand have led to an extensive landscape of gated compounds. In addition to the detached and attached villas within compounds, apartments have been built in the form of low- to medium-rise blocks. The high level of security and the car friendly surroundings made the suburban areas attractive to higher-income groups. Accordingly, many European and Arab respondents have moved to these locations. The low integration of services has however led to significant driving distances.

The third and last housing typology can be found along the new waterfront districts in West Bay and the Pearl development in the North of Doha. The exclusive residential high rise is a rather new phenomenon in Doha. The exclusive apartments in the West Bay district are usually rented by high-income groups and employees with short-term stays. Due to the high attractiveness of certain developments, landlords often prefer short-term tenants to annually increase rents. Both districts West Bay and the newly reclaimed Pearl project have in common that there is a high integration of retail areas and restaurants (Fig. 5). Most respondents living in these typologies are from Europe and the Middle East. No Indian or Filipino respondent has rented an apartment in a waterfront high-rise development, which is a clear indication for income differences as well as the general preference to live in suburban settings in the case of high-income Asian groups.

One of the important findings revealed by the analysis is the housing choices and preferences in terms of location and typology. In the case of the European group, the largest percentage (40\%) has decided for a villa in a compound followed by $28 \%$ living in high-rise developments, mainly along the waterfront (Fig. 6). Less than $15 \%$ of the European group are currently housed in apartment blocks in proximity to Doha's downtown areas. In comparison, approximately $65 \%$ of all Indian respondents and around $65 \%$ of all Filipino respondents reside in areas along the main central ring roads 


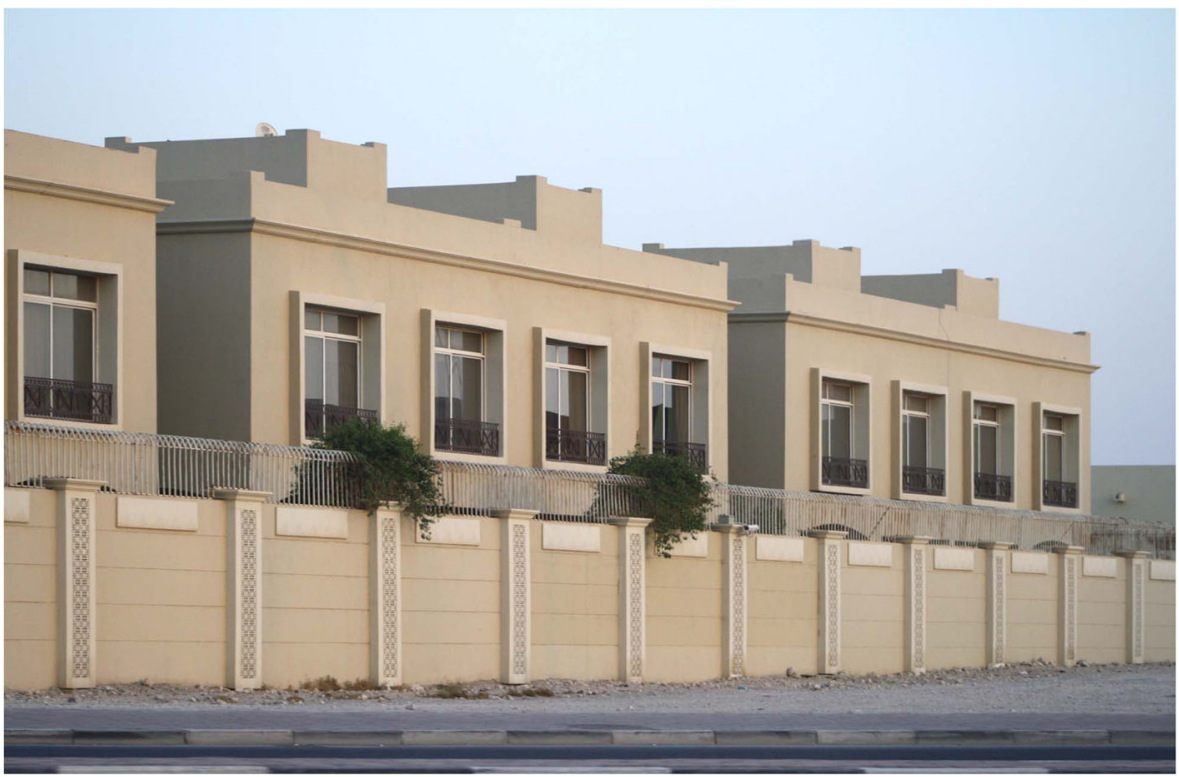

Fig. 4 A typical compound in the suburbs of Doha (source: authors)

(Fig. 7). While Indians have preferred medium rise apartment blocks, an even share of Filipino respondents reside in high-rise buildings of more than ten floors. A similar distribution can be found in the case of respondents from Egypt and the Levant, of whom around $55 \%$ have moved to districts in proximity to Doha's downtown. Moreover, $17 \%$ of the respondents from the Middle East have decided to rent a stand-alone villa in certain areas, which can be attributed to their general familiarity to the environment.

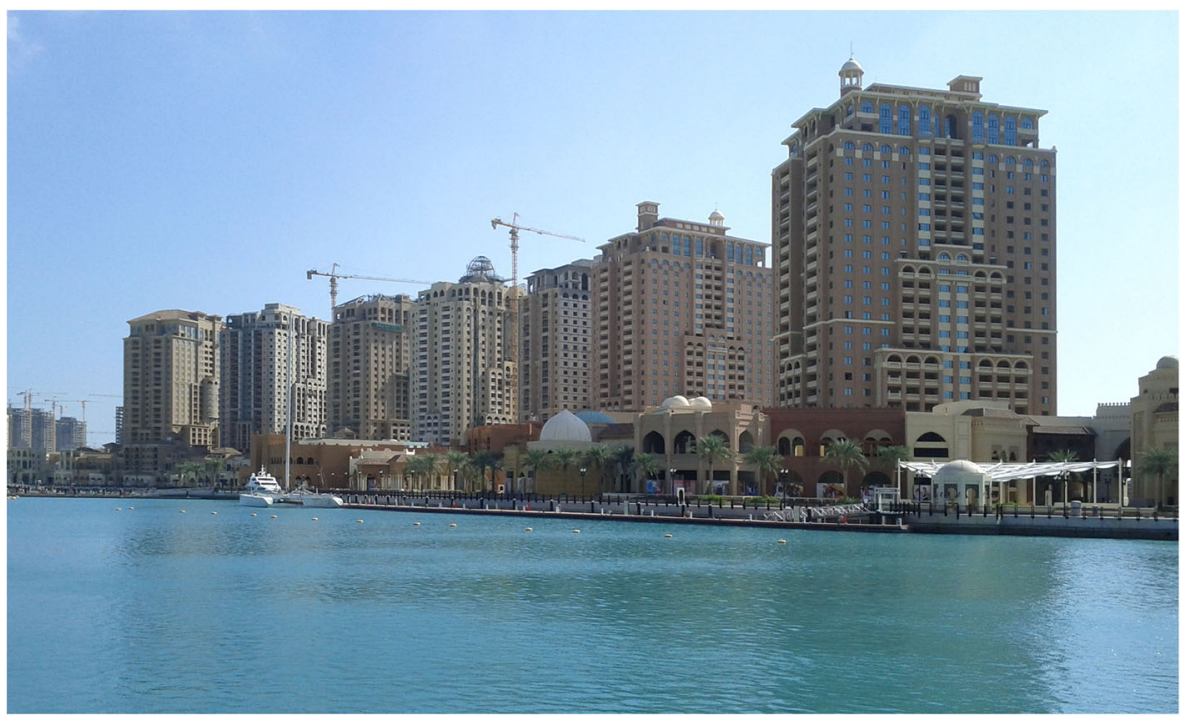

Fig. 5 Residential high rises within the Pearl development site (source: authors) 


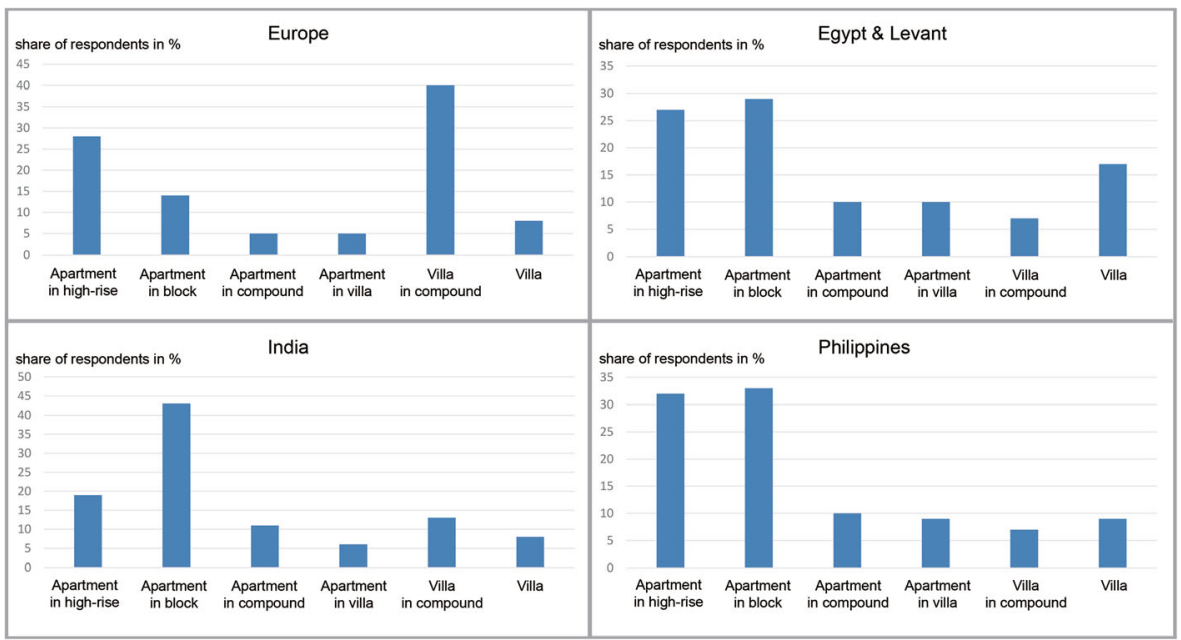

Fig. 6 The chosen housing typologies in relation to the interviewees' region of origin (source: authors)

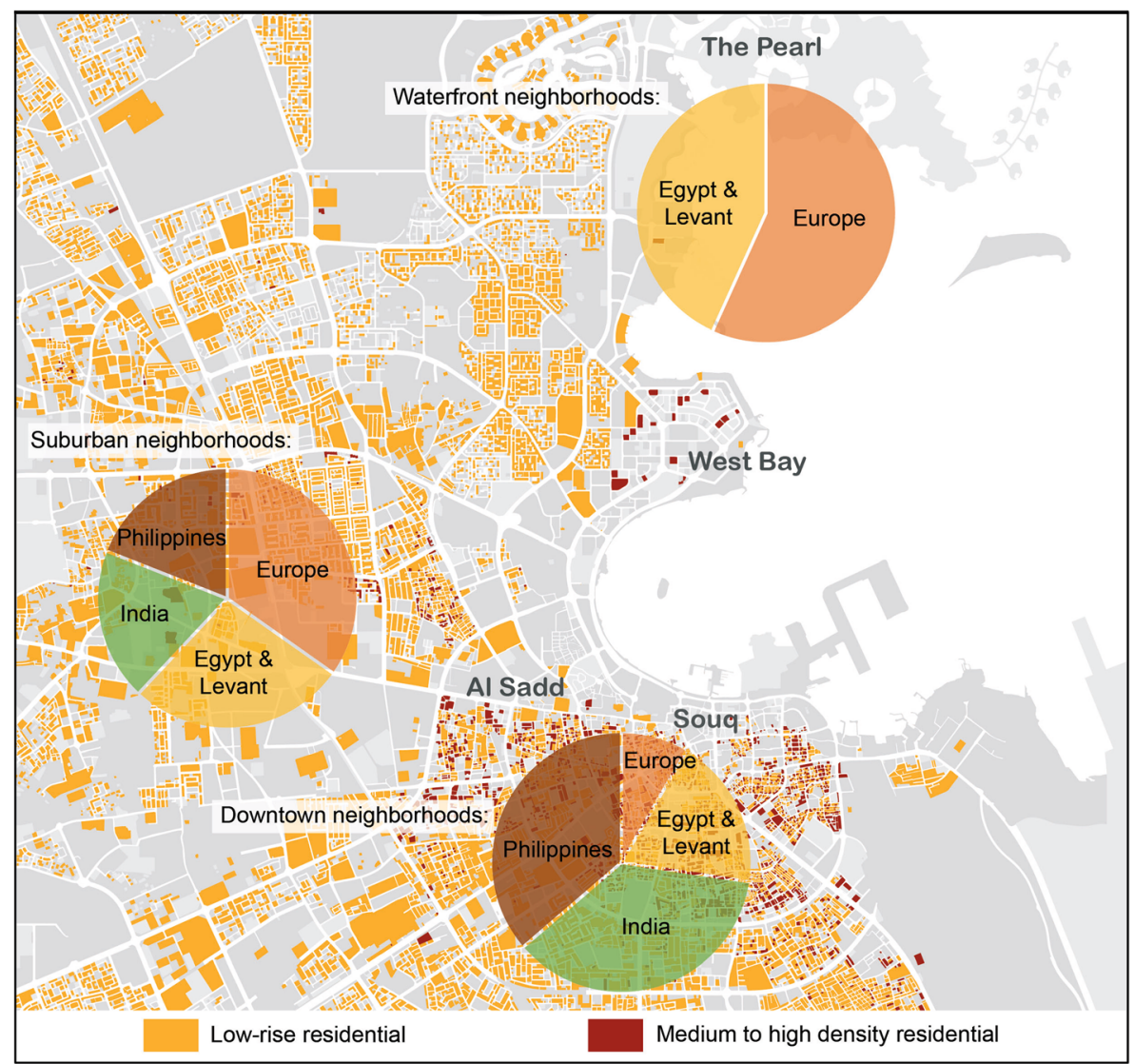

Fig. 7 The spatial distribution of residences in relation to the interviewees' region of origin (source: authors) 


\section{Perceptions of Housing Conditions}

Firstly, the participants were asked about their general satisfaction and perception with respect to the relationship of their current housing conditions and that of their home country. In most cases, respondents are generally satisfied with their current residence in Qatar. The significant share of unsatisfied interviewees could be found in the case of the Indian group of respondents, of which around 20\% identify their housing conditions as dissatisfying. However, the largest share of approximately $40 \%$ of all Indian interviewees perceive their housing conditions as an improvement to their previous housing conditions in India. Most respondents from Europe and the Middle East cannot identify any improvement to the housing conditions in their home countries, but they are generally satisfied and a share of more than $20 \%$ of interviewees experienced an improvement, which can be attributed to the large size of residences in comparison to Europe. In the case of the Filipino group, a large share of more than $90 \%$ is satisfied and almost $40 \%$ would identify a housing improvement since they have moved to Doha (Fig. 7).

Secondly, participants were asked about their satisfaction with respect to general ground floor layouts and rooms sizes. Most Europeans have no complaints, which is an indication of highly spacious living conditions in villas and waterfront developments. Respondents from India, Philippines, and Middle East share their average level of dissatisfaction of approximately $40 \%$ in the case of room sizes; particularly, living rooms are identified as too small in typical inner-city apartments (Fig. 8). The general layout of apartments is mainly criticized by Indian respondents, who have a need for separate kitchens, and respondents from the Middle East, who have a need for separate visitor areas for cultural reasons.

Thirdly, participants had to share their perceptions regarding the quality of utilities and kitchens as well as the supply with sufficient daylight in the interior environment. In the case of utilities, mainly Europeans (32\%) would identify the general quality as dissatisfying due to frequent problems (Fig. 9). The respondents with migrant background from the other three groups seem to be used to the general standard of utilities and have a lower share of complaints (approximately 20\%). However, the frequent problems with sewage, electricity, and water supply can be identified as a general concern across all housing typologies in Doha for the four cultural groups. The most significant share of dissatisfaction in the case of kitchens can be found among Filipino respondents, where $40 \%$ have complaints, followed by the Indian respondents (30\%). This is a clear indication of the low quality in apartment buildings in inner-city areas due to the construction standard as well as the tendency to install low-quality supplies for a more frequent replacement. Almost $30 \%$ of respondents from India identify the availability of daylight in their accommodations as unsatisfying, while Filipinos seem to be most satisfied with present conditions. In addition to the significant share of female employees, this could be another indication that a large share of the Filipino respondents has moved to Doha without their families and that accommodations are mainly used at nights after work hours.

With respect to perceptions of neighborhoods and outdoor environments, less than $35 \%$ of all European respondents would identify their current neighborhoods as pedestrianfriendly, which is both a strong indication that suburban areas, where many Europeans reside, are not walkable due to the limited integration of services and pedestrian walkways. This can be attributed to the high-expected standard of pedestrian-friendly surroundings from a European perspective. Furthermore, more than $80 \%$ of all European respondents 

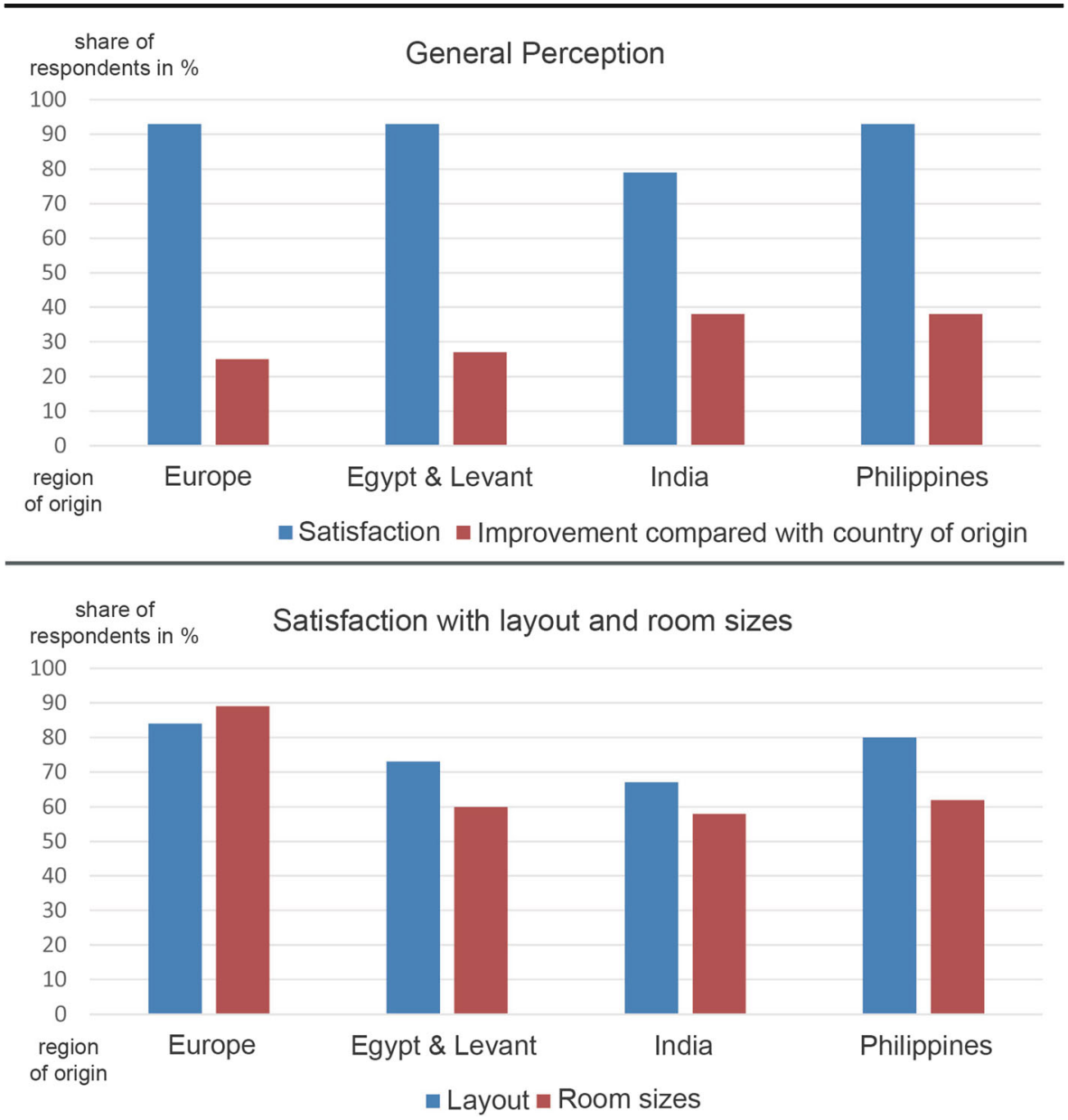

Fig. 8 The general satisfaction of interviewees regarding their residence in Doha and their perceptions of ground floor layouts and room sizes (source: authors)

expressed dissatisfaction with the availability of green spaces in their neighborhoods (Fig. 10). The most complaints about the lack of green areas can be however found in the case of the Indian and Filipino respondents, which is a strong indication that inner-city areas have very few public green areas in walkable distances for most residents. Based on a GIS survey, only $2 \mathrm{~m}^{2}$ of public green area per inhabitant can be found in contemporary Doha. The respondents from the Middle East share the complaints with respect to the supply of green areas around their neighborhoods - however slightly less than the other three groups. They furthermore identify their neighborhoods to a large extent (50\%) as walkable. Indian and particularly Filipino interviewees share this opinion, which is an indication for the high level of general land use integration in inner-city districts, where most of the respondents from these three groups reside.

Perception of neighborhoods as family-friendly most Europeans (75\%) shares the view that their surroundings offer sufficient security and amenities for children (Fig. 10). This relatively high satisfaction rate can be attributed to the quality of the contexts in which most European respondents live; gated communities in suburban areas or 

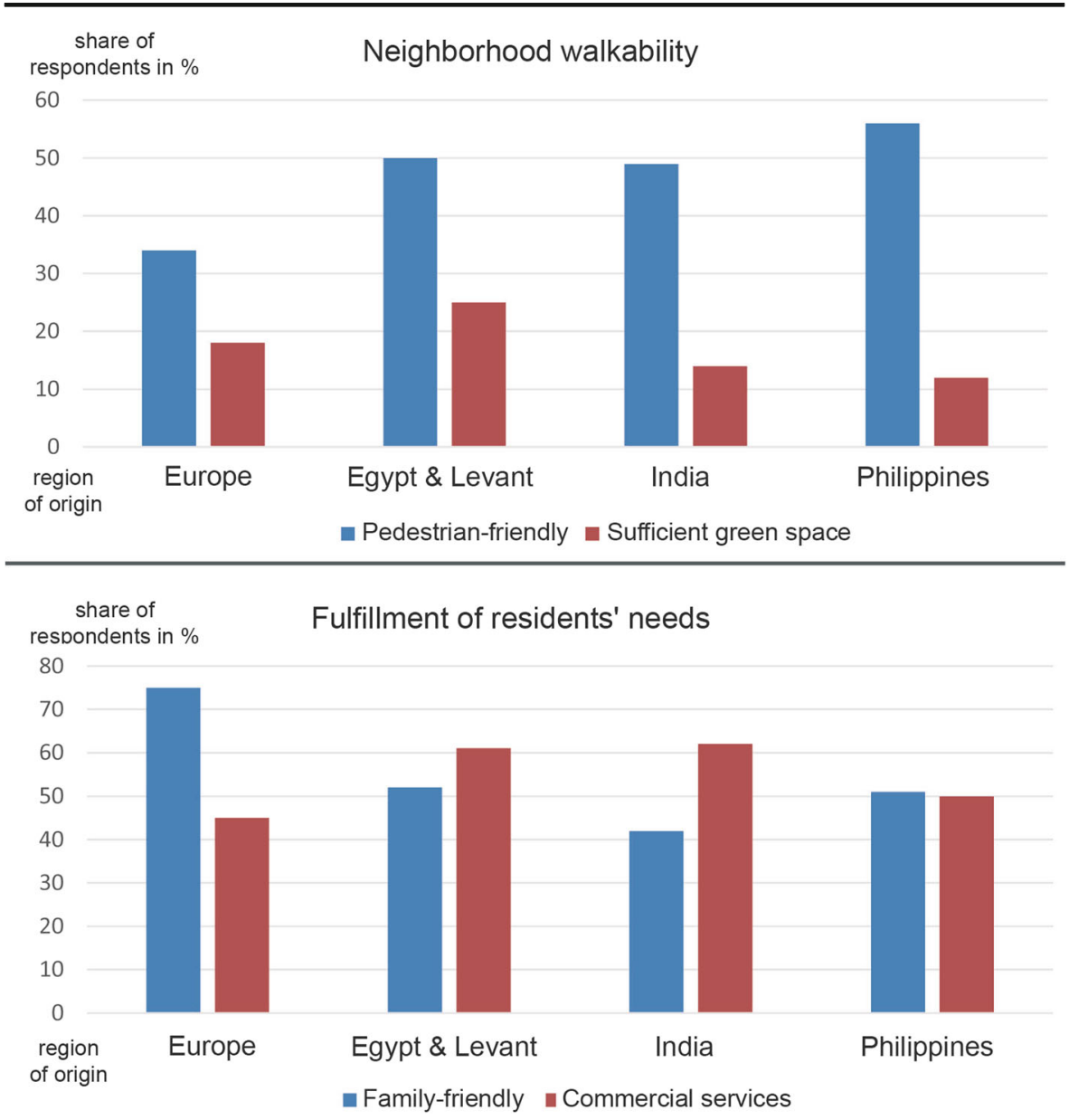

Fig. 9 Perceptions of utilities, kitchens, and daylight in residences (source: authors)

exclusive waterfront developments. Yet, approximately 55\% of all European interviewees complain about a big lack of commercial services, such as supermarkets, in proximity to their homes. This is another evidence of the very little integration of services in suburban areas. Indian respondents perceive their neighborhoods as least family-friendly (68\%) followed by respondents from the Philippines and the Middle East (both approximately 50\%). This can be attributed to the chaotic traffic conditions in inner-city areas and the very few integrated playgrounds and social services. Less than $40 \%$ of Arab and Indian respondents perceive the integration of commercial services as insufficient, while every second Filipino respondent would prefer more commercial services in his or her neighborhood. The relatively high share of dissatisfaction regarding commercial services is particularly related to the lack of grocery stores, which are mainly built as mega stores in malls and at main traffic junctions rather than small to medium size supermarkets equally distributed in districts.

Participants were requested to share their perceptions regarding the current interior and exterior design standards of their residences. While European and Indian respondents expressed dissatisfaction more with the interior than the exterior design, Arab and 

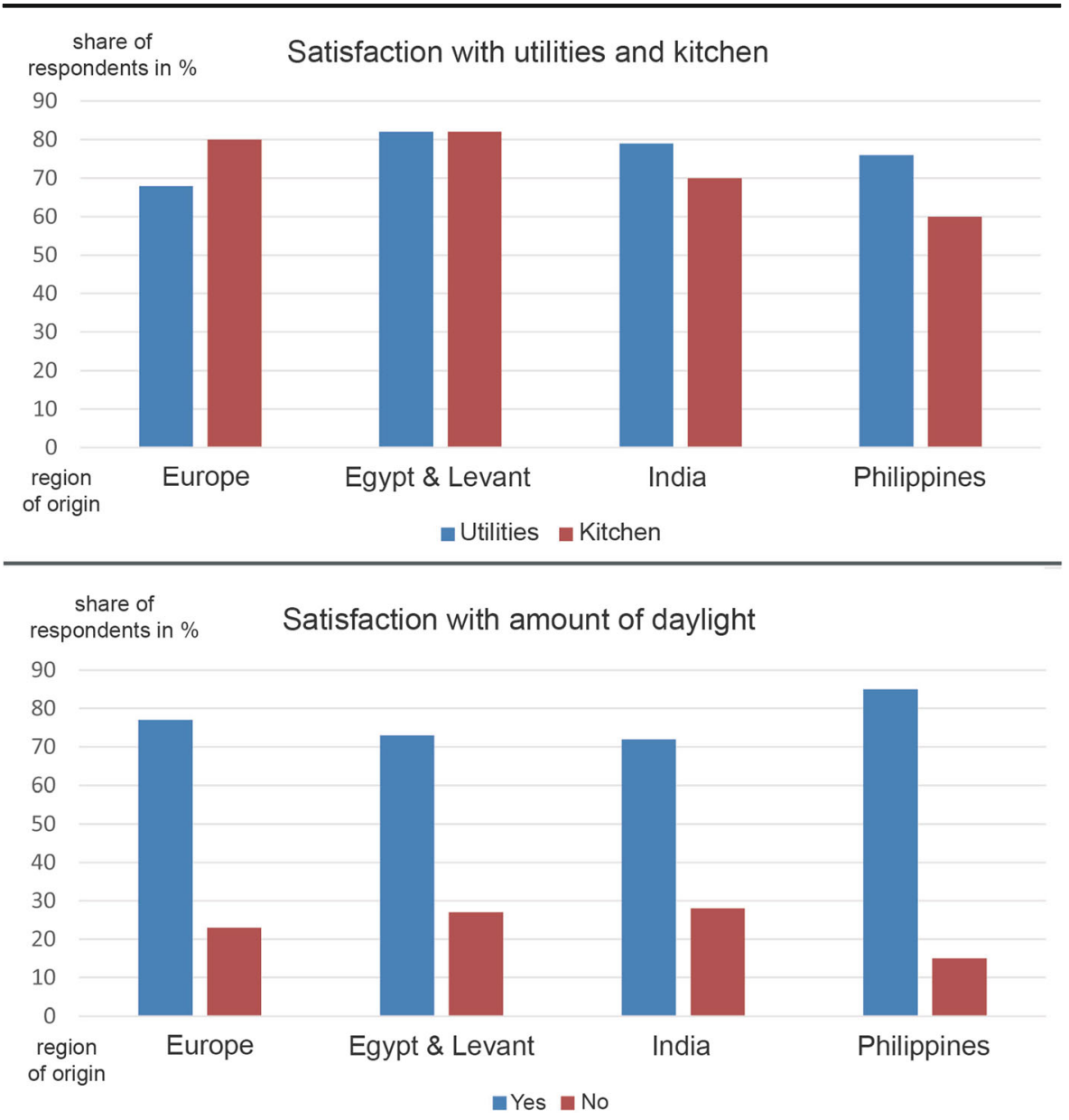

Fig. 10 Perceptions of surrounding neighborhoods (source: authors)

Filipino respondents expressed dissatisfaction with the exterior design. In general, all respondents share an average level of satisfaction in the case of the design standards (approximately 65\%). The highest level of satisfaction (79\%) can be observed in the case of Filipino respondents with respect to the interior design of their accommodations. The least satisfaction (59\%) can be found in the case of the Indian respondents and their views about the exterior design. Even though most European respondents reside in rather exclusive housing projects, there is still a rather high level of dissatisfaction of approximately $40 \%$ in the case of interior and $30 \%$ in the case of exterior design standards (Fig. 11). These findings are another indication that the need for an exponential housing supply led to rather low architectural standards.

\section{Conclusion}

Findings resulted from the analysis of questionnaire responses coupled with field studies offer new understandings of present housing conditions of migrant knowledge 


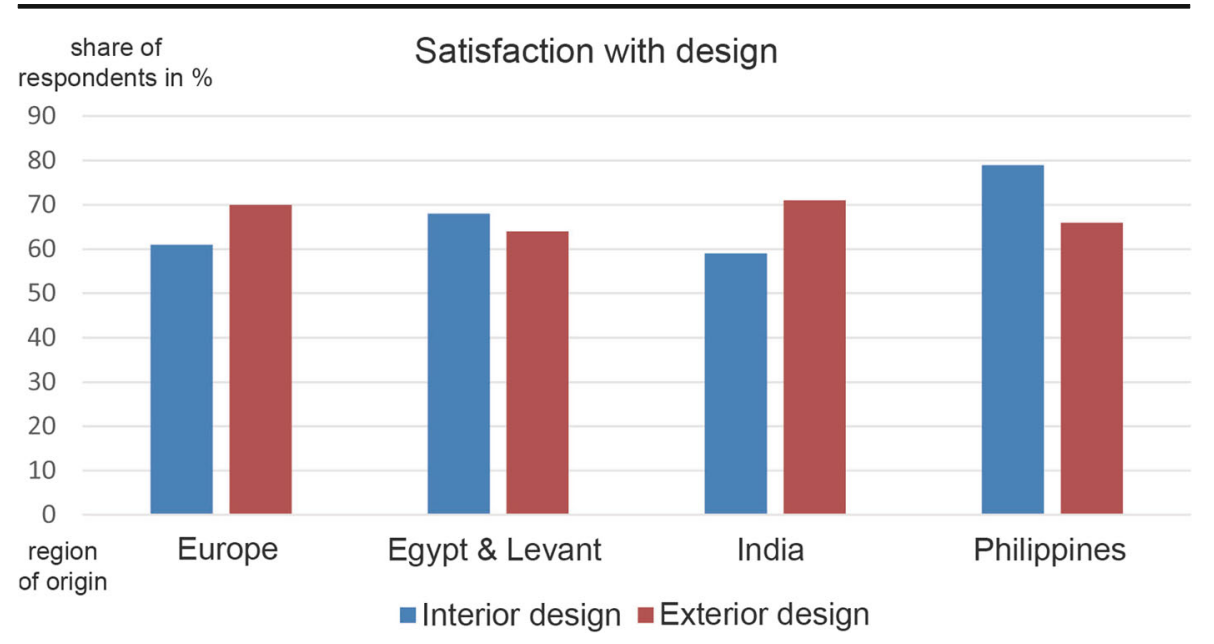

Fig. 11 Perceptions of the architectural design of residences (source: authors)

workers in Doha and the Gulf region in general. The rather short-term stay and high level of exchange of migrant inhabitants have led to very particular housing phenomena, such as the very distinct categories of housing typologies and their locations. While the lowest rents can be found in highly dense areas around and within the old city cores as well as in certain compound developments offering apartments in rather remote locations, the highest rental rates can be found in well-located compounds and exclusive waterfront developments. This general spatial distribution can be witnessed in Gulf cities that it has led to a segregation of income groups, which is associated with the segregation of groups from certain cultural backgrounds. Subsequently, Indian and Filipino have settled in inner-city areas, while new exclusive projects accommodate a large share of migrants from Western countries as well as investors from neighboring GCC countries. The most evenly distributed cultural group is migrants from the Arab region, who are also known for being engaged in almost every economic sector.

The supply-driven mechanisms have led to pragmatic planning decisions, such as the increase of low-rise residential areas in the urban periphery and the permission of high-built densities in very accessible districts in proximity to downtown areas and thus main spatial concentrations of jobs. Furthermore, developers were given limited restrictions to establish an attractive environment for investors. Today, the main challenge of supplying sufficient affordable housing is related to the continuously increasing rental prices, particularly in the case of very accessible locations, which have begun to attract higher-income groups to reduce their daily commutes to their working places and to avoid higher rents in exclusive residential properties. It can be argued that developers have focused on the high-end spectrum of the real estate market, driven by the speculative interest of regional investors, and that the housing markets for lowerand medium-income groups have been struggling to offer quality for affordable rental costs. This has worsened due to the ongoing increase of real estate prices and the subsequently high vacancy rates in certain areas. Housing, which is a decisive factor in the overall livability of any city, is now compromised in many areas and its current situation is a serious threat in developing future communities and thus economies in Gulf cities. 
The frequent exchange of a large part of the migrant inhabitants, who have the largest share of up to $90 \%$ of the entire urban population in Gulf cities, is to a large extent based on short-term working contracts and without provisions for citizen rights, which are often perceived as basic precondition for individual long-term investments. Other factors, particularly in the case of higher-income groups, include the low perception of livability, which is a direct result of the rapid urban growth in recent years and the associated negative consequences, such as low construction standards and frequent traffic congestion.

Gulf cities can be described as migrant cities built by migrants for future migrants, who however remain unknown. Today, most developers have not consciously adjusted their ground floor designs of new housing projects to any cultural particularities from certain migrant groups. The main tendency is to follow basic layouts and ways to reduce construction and maintenance costs. The restricted need for adjusting housing designs to the actual tenants and their preferences is rooted in both no clear vision of a typical long-term tenant or end-user and the supply-driven market dynamics. This has forced migrant communities to adjust to present conditions rather than redefining housing based on their needs and demands. In parallel, national citizens are facing high construction costs and an increasing share of this social minority of the overall urban population is forced to rent and to leave their segregated districts.

Consequently, one of the main challenges of contemporary urban governance in Gulf cities is the development of highly inclusive urban environments offering attractive neighborhoods to a wide range of different incomes as well as cultural groups. According to the respondents, who represent a multicultural sample of an increasing medium to high-income group in a Gulf city, the general housing conditions do not seem to be satisfactory at several levels. All three housing typologies are highly criticized by the respondents in the case of their general design and construction standards, the poor integration of accessible services in neighborhoods and the lack of responsiveness to certain cultural needs. Thus, many new tools and strategies need to be explored with respect to the way in which various housing typologies and neighborhoods can be adjusted, adapted, or upgraded. As well, the exploration of new strategic imperatives and guidance for new developments should be a priority to speak to housing preferences of emerging migrant communities. In future, it is anticipated that enhanced housing standards will play a decisive role in transforming Gulf cities into knowledge economies with a view of the long-term settlement and investment in migrant communities.

Funding information This paper stems from works undertaken as part of two funded research projects of the National Priorities Research Program, QNRF-Qatar National Research Fund (NPRP 09-1083-6023) which was completed in 2014 and (NPRP 7-960-5-135) which is currently ongoing.

Open Access This article is distributed under the terms of the Creative Commons Attribution 4.0 International License (http://creativecommons.org/licenses/by/4.0/), which permits unrestricted use, distribution, and reproduction in any medium, provided you give appropriate credit to the original author(s) and the source, provide a link to the Creative Commons license, and indicate if changes were made.

\section{References}

Abu Dhabi Council for Economic Development (2014). Sustainability—playing a central role in Abu Dhabi's economic growth. The Economic Review. Issue 19. Abu Dhabi.

Al Buainain, F. (1999). Urbanisation in Qatar: a study of the residential and commercial land development in Doha City, 1970-1997. Salford: University of Salford. 
Balbo, M., \& Marconi, G. (2006). International migration, diversity and urban governance in cities of the south. Habitat Int, 30(3), 706-715.

Bertrand, P. (2012). Real estate bubble and financial crisis in Dubai: dynamics and policy responses. Journal of Real Estate Literature, 20(1), 51.

Bonaiuto, M., Aiello, A., Perugini, M., Bonnes, M. \& Ercolani, A. P. (1999). Multidimensional perception of residential environment quality and neighborhood attachment in the urban environment. Journal of Environmental Psychology, 19(4), 331-352.

BQ Magazine (2014). Population of Qatar by nationality. Available at: http://www.bq-magazine. com/economy/2013/12/population-qatar. Accessed 24 Oct 2015.

Butler, E. W., Chaplin, F. S., Hemmens, G. C., Kaiser, E. J., Stegman, M. A. and Weiss, S. F. (1969). Moving behavior and residential choice: a national survey, National Cooperative Highway Research Programs, Report No. 81, Highway Research Board, Washington DC.

Castells, M. (1972). La Question Urbaine. Paris: Maspero.

Choguill, C. L. (1996). Toward sustainability of human settlements. Habitat International, 20(3), 5-8.

Cohen, R. (1981). The new international division of labor, multinational corporations and urban hierarchy. In M. Dear \& A. Scott (Eds.), Urbanization and urban planning in capitalist society (pp. 287-317). London: Methuen.

DESA - Population Division Migration Section, UNICEF (2013). Migration profiles common set of indicators. Available at: https://esa.un.org/miggmgprofiles/indicators/indicators.HTM Accessed 5 Aug 2016.

Dresch, P. (2006). Foreign matter: the place of strangers in gulf society. In J. W. Fox, N. Mourtada-Sabbah, \& M. Al-Mutawa (Eds.), Globalization and the Gulf (pp. 200-222). New York: Routledge.

Florida, R. (2002). The rise of the creative class: and how it's transforming work, leisure, community and everyday life. New York: Perseus Book Group.

Fox, J. W., Mourtada-Sabbah, N., \& Al-Mutawa, M. (2006). Globalization and the Gulf. New York: Routledge.

Friedmann, J. (1986). The world city hypothesis. Development and Change, 17(1), 69-83.

Gardner, A. (2011). Gulf migration and the family. J Arabian Studies, 1(1), 3-25.

General Secretariat of Development Planning. (2008). Qatar National Vision 2030. Doha: Gulf Publishing and Printing Company.

Harvey, D. (1973). Social justice and the city. London: Edward Arnold.

Hui, E. C. M., Li, S. M., Wong, F. K. W., Yi, Z., \& Yu, K. H. (2012). Ethnicity, cultural disparity and residential mobility: empirical analysis of Hong Kong. Habitat International, 36(1), 1-10.

Mirincheva, V., Wiedmann, F., \& Salama, A. M. (2013). The spatial development potentials of business districts in Doha. Open House Int, 38(4), 16-26.

Owuso, T. Y. (2010). Residential patterns and housing choices of Ghanaian immigrants in Toronto, Canada. Housing Studies, 14(1), 77-97.

Salama, A. M. (2011). Identity flows, the Arabian Peninsula, emerging metropolises. In Atlas Architectures of the 21st Century Africa and Middle East (pp. 170-221). Madrid: Fundacion BBVA.

Salama, A. M., \& Wiedmann, F. (2013). Demystifying Doha: on architecture and urbanism in an emerging city. Surrey: Ashgate Publishing Limited.

Salama, A. M., Wiedmann, F., Thierstein, A., \& Al Ghatam, W. (2016). Knowledge economy as an initiator of sustainable urbanism in emerging metropolises: the case of Doha, Qatar. Int J Architectural Res, 10(1), 274-324.

Sanderock, L. (1998). Towards cosmopolis: planning for multicultural cities. Chichester: John Wiley \& Sons.

Sassen, S. (1988). The mobility of labor and capital. A study in international investment and labor flow. Cambridge: Cambridge University Press.

Sassen, S. (1991). The global city. New York, London, Tokyo. Princeton: Princeton University Press.

Schmid, H. (2009). Dubai: Der schnelle Aufstieg zur Wirtschaftsmetropole. In E. Blum \& P. Neitzke (Eds.), Dubai-Stadt aus dem Nichts (pp. 56-73). Berlin: Birkhäuser.

Scholz, F. (1999). Die kleinen Golfstaaten. 2nd ed. Gotha: Justus Perthes Verlag Gotha GmbH.

Sulayman, K. (2006). The evolution of the Gulf City type: oil and globalization. In J. W. Fox, N. MourtadaSabbah, \& M. Al-Mutawa (Eds.), Globalization and the Gulf (pp. 245-263). New York: Routledge.

Taylor, P. J. (2003). World city network: a global urban analysis. London: Routeledge.

Ukoha, O. M., \& Beamish, J. O. (1997). Assessment of residents' satisfaction with public housing in Abuja, Nigeria. Habitat International, 21(4), 445-460.

Wiedmann, F. (2012). Post-oil urbanism in the Gulf: new evolutions in governance and the impact on urban morphologies. Stuttgart: SVH Verlag.

Wiedmann, F., Mirincheva, V., \& Salama, A. M. (2013). Urban reconfiguration and revitalisation: public mega projects in Doha's historic centre. Open House Int, 38(4), 27-36.

Wiedmann, F., Mirincheva, V., \& Salama, A. M. (2014). Sustainable urban qualities in the emerging city of Doha. Journal of Urbanism, 7(1), 62-84. 